\title{
Feelings of Ownership in Dictator Games
}

\author{
Oleg Korenok, Edward Millner and Laura Razzolini*
}

Virginia Commonwealth University

\begin{abstract}
This paper determines if differences in feelings of ownership mediate the effect of changing who earns the endowment and the frame of actions on dictators' generosity. We conduct an experiment with two treatments. The Dictator Earns-Give treatment is designed to induce strong feelings of ownership, while the Recipient Earns-Take treatment induces weak feelings of ownership. We measure feelings of ownership in the two treatments. As expected, dictators report stronger feelings of ownership in the first treatment and these feelings mediate the dictator's generosity. Moving from the Recipient Earns-Take treatment to the Dictator EarnsGive treatment indirectly reduces the payoff to the recipient by increasing the dictators' feelings of ownership.
\end{abstract}

Keywords: dictator game; feelings of ownership; altruism JEL Classification Codes: C72, C91, D03

* Research support provided by the Templeton Foundation's "Science of Philanthropy Initiative" to Millner and Razzolini, and the VCU Presidential Research Incentive Fund to Millner is gratefully acknowledged. Any remaining errors are our own. Corresponding author: Edward Millner, emillner@vcu.edu , Richmond VA 23284-4000. 


\section{Introduction}

The attributes of dictator games affect dictators' generosity. One attribute that affects generosity is whether the dictator earns the endowment or receives it as a windfall. Dictators are less generous when they earn the endowment. Cherry (2001) reports that when dictators earn the endowment, the average gift is 3.04\% of the endowment, Cherry, Frykblom, Shogren (2002) report that the average gift is about 5\% of the endowment, and Oxoby and Sparragon (2008) report a $0 \%$ gift. On the other hand, when dictators do not earn but are simply given the endowment, the average gift is usually around $25 \% .{ }^{1}$ Another attribute that affects generosity reported in other studies is whether the decision is framed as giving to the recipient or as taking from the recipient. Korenok, Millner and Razzolini (2014), Oxoby and Sparragon (2008), and Cox, List, Price, Sadiraj and Samek (2015) find that the average gift is greater in the taking game.

In this paper we ask why earning the endowment and changing the frame of actions affect dictators' generosity. The literature suggests a potential explanation: differences in the attributes of the game define different property rights over the endowment. Cherry, Frykblom, Shogren (2002) speculate that the actions of the dictators, at least partially, are driven by the legitimacy of the wealth. Dreber, Ellingsen, Johannesson, and Rand (2013) hypothesize that the recipients would get more money in the take frame, because dictators would be relatively averse to taking, as taking could be considered a violation of the recipient's entitlement. Oxoby and Sparragon (2008) "conjecture that the legitimizing of assets creates property rights which participants observe" (p. 704). Similarly, Banerjee and Chakravarty (2014) suggest that the sense of personal property induced by earning reduces the amount given by dictators.

"Feelings of ownership" rather than "property rights" more precisely characterize the consequences of the different attributes. In economics, property rights are defined as "the exclusive authority to determine how a resource is used" (Alchian, 2008) and in law a common criteria of property rights is ". .. if one person holds a 'right' to something, at least one other person must have a corresponding duty not to interfere with her possession and use" (Cole and Grossman, 2002, p. 318). Earning or not earning the endowment does not change the dictator's exclusive authority to determine how the endowment is used. Similarly, the different frames of the game do not change the recipient's duty not to interfere with the use of the endowment chosen by the dictator. Therefore, earning or not earning the endowment and the giving or taking frames do not modify the property rights, as defined in economics or law. Property rights always reside with the dictator. However, feelings of ownership may change across different attributes of the game. A dictator that earned the endowment may have strong feelings of ownership. Similarly, a dictator may have weak feelings of ownership over an endowment earned by the recipient. These feelings of ownership, in turn, may affect the dictator's behavior.

\footnotetext{
${ }^{1}$ Using a meta-study, Engel (2011) reports that in a traditional dictator game, on average, $70 \%$ of dictators give a positive amount and the average gift is about $25 \%$ of the dictator's endowment.
} 
Studies not involving dictator games find that the institutional changes associated with feelings of ownership affect behavior. Hoffman and Spitzer (1985) find that earning the right to control affects decisions in bargaining games. Hoffman, McCabe and Smith (1994) find that earning both the right to be the first mover and the endowment affects decisions in ultimatum games. Bushong, King, Camerer and Rangel (2010), Knetsch and Wong (2009), Peck and Shu (2009) and Reb and Connolly (2007) report that being present with the item or touching it increase the endowment effect.

In this paper, we conduct a dictator game experiment with two treatments designed to maximize the differences in feelings of ownership: in the first treatment, the dictator earns the endowment and gives; in the second treatment, the recipient earns the endowment and the dictator takes. We use a questionnaire developed by psychologists to measure the feelings of ownership in the two treatments. We find that feelings of ownership mediate the effect of the changes in the treatments on dictators' generosity; having the dictator earn the endowment, possess it, and give indirectly reduces the payoff to the recipient by increasing the dictators' feelings of ownership.

\section{Experimental Design, Model and Hypotheses}

Pierce, Kostova and Dirks (2003) define "psychological ownership as the state in which individuals feel as though the target of ownership or a piece of that target is 'theirs' (i.e., 'It is mine!')" (p. 86). They "propose three major experiences (i.e., routes, paths, and mechanisms) through which psychological ownership emerges: controlling the ownership target (object), coming to know the target intimately and investing the self in the target” (p. 92.). In dictator games, by design the dictator has control over the endowment, as he/she is the sole decision maker. Thus, controlling the ownership target cannot be changed. We use the two remaining paths to change the feelings of ownership over the endowment in the laboratory: Let the participant come to know the target by touching and possessing the endowment; Allow the participant to invest the self in the target by earning the endowment.

Feelings of ownership were elicited in the laboratory by having all participants complete a questionnaire. The questionnaire asked participants to rate their agreement or disagreement with a series of statements about the money distributed in the game. The rating used a 7-point scale ranging from 1 (Strongly Disagree) to 7 (Strongly Agree). The questions were:

1. I feel like this is my money.

2. I feel a very high degree of personal ownership of this money.

3. I feel like I own this money.

4. I feel like this is another person's money.

5. I feel like another person has a very high degree of personal ownership of this money. 
6. I feel like another person owns this money.

7. I think that another person feels like this is her money

8. I think that another person feels a very high degree of personal ownership of this money.

9. I think that the other person feels like she owns this money.

Questions 1-3 were used to measure psychological ownership by Peck and Shu (2009) who in turn adapted Pierce, Kostova and Dirks's (2001) questions. Questions 1-3 elicit how strongly the participant feels that the money is theirs. Questions 4-9 are small modifications of questions 1-3. Questions 4-6 elicit how strongly the participant feels that the money is someone else's.

Questions 7-9 elicit how strongly the participant thinks that someone else feels that the money is someone else's. High ratings on questions 1-3 indicate strong feelings of ownership, while high ratings on questions 4-6 and 7-9 indicate weak feelings of ownership.

We run an experiment with two treatments of an otherwise similar dictator game, with experimental design and procedures based on Oxoby and Sparragon (2008). The two treatments are Dictator Earns-Give and Recipient Earns-Take. In the two treatments, either the dictator or the recipient earns the endowment by answering questions drawn from the GMAT and GRE tests. The amount earned varies from $\$ 10$, to $\$ 20$, to $\$ 40$, depending on the number of correct answers. After taking the test and earning the money, the participant counts the money and puts it in his/her wallet, pocket or purse.

The Dictator Earns-Give treatment is designed to induce strong feelings of ownership in dictators through the two primary paths of investing self and intimate knowledge. In this treatment, the dictator invests self in the target by earning the endowment. Also the dictator comes to know the target intimately by taking the money and putting it into a wallet, pocket or purse. At the end of the experiment, the dictator gives to the recipient. The Recipient Earns-Take treatment uses the same paths to induce strong feelings of ownership in recipients and weak feelings of ownership in dictators. The recipient earns the endowment, takes the money and puts it into a wallet, pocket or purse, and later the dictator takes from the recipient. Since in this treatment the dictator neither invests self nor has intimate knowledge of the target and is fully aware that the recipient did invest self and has intimate knowledge of the target, the dictators' feelings of ownership should be weak. Figure 1 summarizes the model. The parameter $a$ indicates the effect of the treatment on feelings of ownership, $b$ the effect of feelings of ownership on the recipient's payoff and $c$ ' the direct effect of treatment on recipient's payoff.

Oxoby and Sparragon report that the direct effect of changing from the Recipient Earns-Take treatment to Dictator Earns-Give is negative: the payoff to the recipient is significantly lower in Dictator Earns-Give. Our hypothesis is that the changes in the feelings of ownership $(a b)$ mediate this effect. 


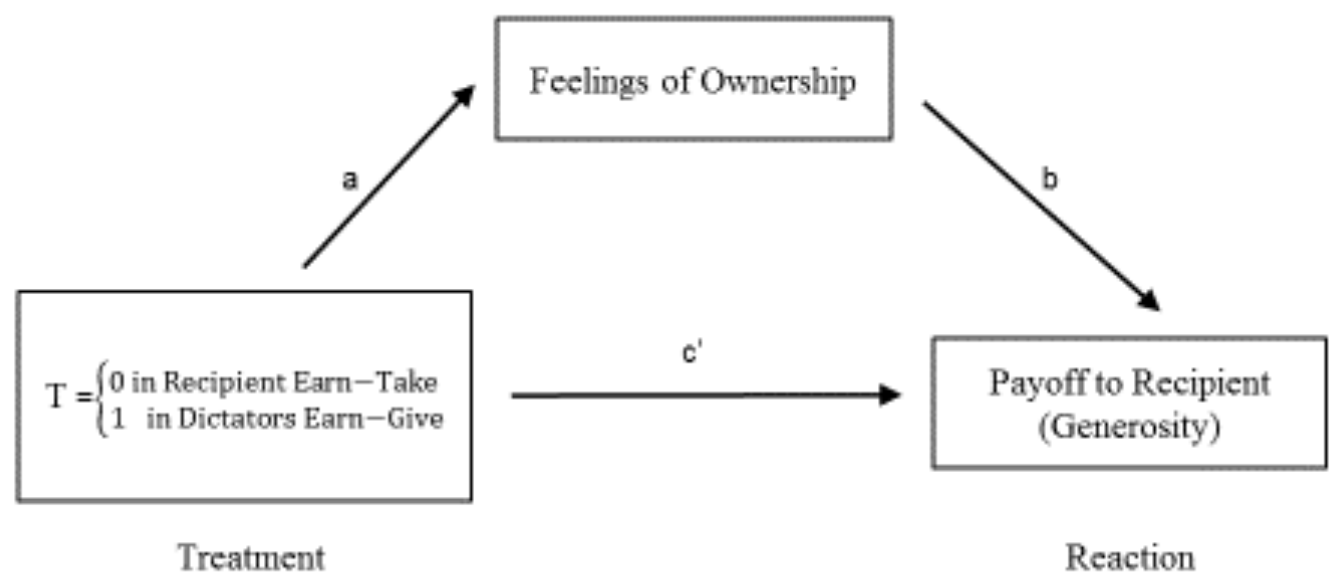

Figure 1

The ORSEE software developed by Greiner (2015) was used to recruit participants and to schedule sessions. Only inexperienced subjects were recruited to the experiment. Dictators and recipients were never in close proximity and reported to different rooms. Both rooms contained cubicles to prevent participants from observing the decisions other participants were making. Participants who earned the money reported 45 minutes before the participants who did not. The instructions for the dictators described the instructions for the recipients and vice versa. The Appendix contains the instructions.

A total of 12 sessions were conducted at Virginia Commonwealth University, with students recruited mostly from upper level business and economics courses: sessions 4, 5, 10, 11, and 12 implemented the Dictator Earns-Give treatment and sessions 1, 2, 3, 6, 7, 8, and 9 the Recipient Earns-Take treatment. A total of 268 subjects participated in the experiment, 126 in the Dictator Earns-Give and 146 in the Recipient Earns-Take treatment. On average participants earned $\$ 11.01$. See Table 1 for a summary of subjects' demographics.

Table 1: Subjects' Characteristics

\begin{tabular}{ccc}
\hline & & \\
& $\mathrm{N}$ & $\begin{array}{c}\text { Female } \\
(\%)\end{array}$ \\
\hline All Subjects & 268 & 57.68 \\
Dictators & 134 & 59.70 \\
Recipients & 134 & 55.64 \\
\hline Students'Major & & \\
Business/Economic & 78 & 29.49 \\
Science/Math/Engineering & 65 & 69.23 \\
Humanities & 39 & 82.18 \\
Other & 86 & 61.18 \\
\hline
\end{tabular}


All participants completed the questionnaire designed to elicit feelings of ownership. The questionnaire can be found in the Appendix. Recipients always completed the questionnaires after the instructions were read out loud. Dictators in sessions 1, 2, 3, 4, 5, 6, 12 completed the questionnaire at the end of the experiment, while dictators in sessions 7, 8, 9, 10, 11 completed the questionnaire after the instructions were read but before making the allocation decision.

We administered the questionnaire to the dictators at two different points during the experiment to test whether the allocation decisions are independent of the responses to the questionnaire. Dictators who give little or take much might adjust the answers to the questionnaire to justify their action to themselves or the experimenter by declaring strong feelings of ownership. We fail to find statistically significant differences in the responses to the questionnaire or in the allocation decisions between the dictators who completed the questionnaire at the end of the experiment and those who completed it earlier in the session. To test for differences, we use twosample t-tests with unequal variances with the null hypothesis of equality of means. ${ }^{2}$ In the Dictator Earns-Give treatment, the t-statistic for the final allocation received by recipient is 0.8819 (p-value 0.3813); the t-statistic for answers to questions Q1-Q3 is 0.1792 (p-value 0.8583), -0.0579 (p-value 0.9540) for questions Q4-Q6 and 1.4453 (p-value 0.1539) for questions Q7-Q9. Similarly, in the Recipient Earns-Take treatment, the t-statistic for the final allocation is 0.1408 with (p-value 0.8884 ); the t-statistic for answers to questions Q1-Q3 is 0.1792 (p-value 0.8583), 0.2734 (p-value 0.7853 ) for questions Q4-Q6 and 11.4670 (p-value 0.1468 ) for questions $\mathrm{Q} 7-\mathrm{Q}$ 9. We, therefore, pool the outcomes from both sets of dictators in the analysis of the results.

\section{Results}

Table 2 summarizes the responses to the questionnaire and shows the percentage of endowment received by dictators and recipients. For example, Row 1 shows that the dictators' mean response to questions 1-3 is 5.12 in the Dictator Earns-Give treatment, while the recipients' mean response is 3.06. Rows 7 and 8 show that in the Dictator Earns-Give treatment the recipient receives on average $15 \%$ of the endowment, while in the Recipient Earns-Take treatment the recipient keeps on average $40 \%$ of the endowment.

Feelings of ownership change as expected. In the Dictator Earns-Give treatment, when dictators earn the money, both dictators and recipients feel that dictators own the money. Also, both dictators and recipients perceive that the recipient does not own the money. In the Recipient Earns-Take treatment, when recipients earn the money, both dictators and recipients feel that recipients own the money; also both perceive that dictator does not own the money.

\footnotetext{
${ }^{2}$ These results are robust to using the Wilcoxon rank-sum (Mann-Whitney) and the Kolmogorov-Smirnov tests.
} 
Table 2: Means by Decision and Type of Experiment

\begin{tabular}{ccllll}
\hline Row & & Decision & Dictator & Recipient & t-test \\
\hline 1 & Dictator Earns-Give & Q1-Q3 & $5.12^{*}$ & 3.06 & $7.1742(\mathrm{p}=0.000)$ \\
2 & Dictator Earns-Give & Q4-Q6 & 2.65 & $5.21^{*}$ & $-8.6302(\mathrm{p}=0.000)$ \\
3 & Dictator Earns-Give & Q7-Q9 & 3.34 & $5.64^{*}$ & $-8.6352(\mathrm{p}=0.000)$ \\
\hline 4 & Recipient Earns-Take & Q1-Q3 & 3.13 & $5.28^{*}$ & $-7.3949(\mathrm{p}=0.000)$ \\
5 & Recipient Earns-Take & Q4-Q6 & $4.97 *$ & 2.93 & $7.8831(\mathrm{p}=0.000)$ \\
\hline 6 & Recipient Earns-Take & Q7-Q9 & $5.94 *$ & 4.34 & $6.4760(\mathrm{p}=0.000)$ \\
\hline 7 & Dictator Earns-Give & Allocation & $85 \%$ & $15 \%$ & \\
\hline & Recipient Earns-Take & Allocation & $60 \%$ & $40 \%$ & \\
\hline
\end{tabular}

* Significantly greater than the other value in the row at the 5\% level, based on a two-sample t-test with unequal variances with the null hypothesis of equal means for dictators and recipients.

Since our experimental treatment is similar to that of Oxoby and Sparragon (2008), we first check if our results confirm Oxoby and Sparragon's. Row 7 in Table 2 shows that in the Dictator Earns-Give treatment the recipient gets on average $15 \%$ of the endowment. In an equivalent treatment, Oxoby and Sparragon report 0\%. Thus, like Oxoby and Sparragon we find that earning the endowment result in low rates of giving. Row 8 in Table 2 shows that in the Recipient Earns-Take treatment the recipient keeps on average $40 \%$ of the endowment. In an equivalent treatment, Oxoby and Sparragon report 44\%. Again, like Oxoby and Sparragon we find that when recipient earns the endowment their final payoffs increase. Thus, just like in Oxoby and Sparragon, we confirm that recipients' final payoffs depend greatly on whether the endowment is earned by the dictator or the recipient.

The following is the main result of our paper:

Result 1: Feelings of ownership mediate the effect on the recipients'final payoffs as treatment changes from the Recipient Earns-Take to the Dictator Earns-Give treatment. This change increases the dictators' feelings of ownership, which in turn reduce the payoff to the recipient.

We estimate a simple mediation model to determine whether the two treatments affect the recipients' final payoffs through the dictator's feelings of ownership (Hayes, 2013). We estimate the following three regression equations:

$$
\begin{aligned}
& \pi_{R}=i_{1}+c T+e_{1} \\
& F=i_{2}+a T+e_{2} \\
& \pi_{R}=i_{3}+c^{\prime} T+b F+e_{3},
\end{aligned}
$$


where $F$ denotes feelings of ownership, $T=0$ if the treatment is Recipient Earns-Take and 1 if the treatment is Dictator Earns-Give, $\pi_{\mathrm{R}}$ is the payoff to the recipient and $i_{j}$ and $e_{j}(j \in\{1,2,3\})$ are, respectively, intercepts and random error terms. We use the mean response to questions Q1Q9 as the mediator, with the following transformation: since high ratings on questions 1-3 indicate strong feelings of ownership and high ratings on questions 4-9 indicate weak feelings of ownership, we reverse the scale for questions 4-9 (for example, we record 7 as 1, 6 as 2, and so on). Cronbach's alpha for the mean response to questions Q1-Q9 is 0.93, which indicates a high degree of reliability for our scale. Table 3 reports the mediation model estimates.

Table 3: Results of Mediation Analysis

Total effect model

\begin{tabular}{lccc}
\hline & \multicolumn{3}{c}{ Outcome variable: payoff to recipient $\left(\pi_{\mathrm{R}}\right)$} \\
\cline { 2 - 4 } & $B(S E)$ & $t$ & $p$ \\
\hline Constant & $0.398(0.030)$ & 13.137 & 0.000 \\
Treatment $(T)$ & $-0.251(0.045)$ & -5.626 & 0.000
\end{tabular}

Direct effect model

\begin{tabular}{lccc}
\hline & \multicolumn{3}{c}{ Outcome variable: } \\
\cline { 2 - 4 } & $B(S E)$ & $t$ & $p$ \\
\hline Constant & $2.776(0.148)$ & 18.770 & 0.000 \\
Treatment $(T)$ & $2.301(0.218)$ & 10.542 & 0.000
\end{tabular}

Indirect effect model

\begin{tabular}{lccc}
\hline & \multicolumn{3}{c}{ Outcome variable: payoff to recipient $\left(\pi_{\mathrm{R}}\right)$} \\
\cline { 2 - 4 } & \multicolumn{1}{c}{$B(S E)$} & $t$ & $p$ \\
\hline Constant & $0.600(0.054)$ & 11.072 & 0.000 \\
Feelings of ownership $(F)$ & $-0.073(0.017)$ & -4.387 & 0.000 \\
Treatment $(T)$ & $-0.083(0.057)$ & -1.468 & 0.144
\end{tabular}

Indirect effect of treatment on payoff to recipient

\begin{tabular}{lccc}
\hline Mediator & B (Boot SE) & Boot LL 95\% CI & Boot UL 95\% CI \\
\hline Feelings of ownership $(F)$ & $-0.168(0.042)$ & -0.260 & -0.089 \\
\hline \multicolumn{2}{c}{ Notes: All estimates were computed using PROCESS (Model 4) in SPSS 22. }
\end{tabular}

Notes: All estimates were computed using PROCESS (Model 4) in SPSS 22.

Table 3 confirms that moving from the Recipient Earns-Take treatment to the Dictator EarnsGive treatment indirectly reduces the payoff to the recipient by increasing the dictators' feelings of ownership. Dictators who earn the money give $25 \%$ less to recipients than those who did not $(c=-0.251)$, dictators who earn the money have stronger feelings of ownership than those who 
did not $(a=2.301)$ and dictators with stronger feelings of ownership give less to recipients $(b=$ 0.073). The mediation is statistically significant and complete. A bias-corrected bootstrap confidence interval for the indirect effect $(a b=-0.168)$ based on 5,000 samples is below zero [$0.260,-0.089]$. A confidence interval for the direct effect $\left(c^{\prime}=-0.083\right)$ includes zero $[-0.196$, $0.029] .^{3}$

We close the section on results by examining further how the two treatments affect feelings of ownership. We anticipate that the feelings of ownership expressed by recipients varies inversely with the dictator's feelings of ownership.

Result 2: Recipients have stronger feelings of ownership in the Recipient Earns-Take treatment than in the Dictator Earns-Give treatment.

Consider the mean responses to questions 1-3 by recipients in Rows 1 and 4 of Table 2 . The mean response is 5.28 for the Recipient Earns-Take treatment and is 3.06 for the Dictator EarnsGive treatment. The difference is statistically significant at the 5\% significance level. The tstatistic based on a two-sample t-test with unequal variances with the null hypothesis of equal means is 7.8065 (p-value 0.0000).

Result 3: In the Dictator Earns-Give treatment, the dictators'feelings of ownership are stronger than the recipients'.

Consider Row 1 in Table 2. The mean response to questions 1-3 is 5.12 for dictators and 3.06 for recipients. The difference is statistically significant at the 5\% significance level. As shown in Table 2, the t-statistic is -7.1742 (p-value 0.0000).

Result 4: In the Recipient Earns-Take treatment, the recipients'feelings of ownership are stronger than the dictators'.

Consider Row 4 in Table 2. The mean response to questions 1-3 is 3.13 for dictators and 5.28 for recipients. The difference is statistically significant at the 5\% significance level. As shown in Table 2, the t-statistic is -7.3949 (p-value 0.0000).

\footnotetext{
${ }^{3}$ To ensure robustness of our results, we also estimate three simple mediation models using as mediators answer to Q1-Q3, Q4-Q6, and Q7-Q9. The bias-corrected bootstrap confidence interval for the indirect effect based on 5,000 samples for Q1-Q3 is [-0.152, -0.042], [-0.203, -0.054] for Q4-Q6, and [-0.168, -0.009] for Q7-Q9. We also estimate a parallel multiple mediator model using Q1-Q3, Q4-Q6, and Q7-Q9. The confidence interval for the combined effect is [-0.248, -0.061]. Unlike simple mediation models, in the parallel multiple model, mediation is both statistically significant and complete.
} 


\section{Conclusion and Discussion}

This paper determines if differences in feelings of ownership mediate the effect of changing who earns the endowment and the frame of actions on dictators' generosity. We conduct an experiment with two treatments. The Dictator Earns-Give treatment is designed to induce strong feelings of ownership, while the Recipient Earns-Take treatment induces weak feelings of ownership. We measure feelings of ownership in the two treatments. We conclude that feelings of ownership is a mediator; moving from the Recipient Earns-Take treatment to the Dictator Earns-Give treatment indirectly reduces the payoff to the recipient by increasing the dictators' feelings of ownership.

Our results are consistent with studies that compare behavior in dictator games across cultures. Baumard et al. (2013) compare giving in societies with group property rights to societies with individual property rights. In societies in which individuals tend to own property, "dictators behave as if they assumed that the money is theirs" (2013, p. 70).

Additionally, Baumard et al. (2013, p. 70) state that the failure of the standard dictator game to convey clear feelings of ownership may cause the observed variability in dictator giving. A similar ambiguity may confound studies that compare giving and taking games. Perhaps the experimental procedures used by Oxoby and Sparragon (2008) and Korenok, Millner, and Razzolini (2014) create differences in the dictators' feelings of ownership, while the procedures used by Grossman and Eckel (2015), Dreber, Ellingsen, Johanneson and Rand (2013) and Kettner and Waichman (2016) do not. Subtle changes matter. For example, Banerjee, Priyodorshi and Sujoy Chakravarty (2014) report that changing the description of the ownership of the endowment can affect dictator behavior. Brañas-Garza (2007) reports that adding the sentence, "Note that he relies on you", to the instructions increases the generosity of dictators.

The three studies that fail to find a difference in outcomes between giving and taking games use procedures that reduce the differences in feelings of ownership. In all three studies the instructions fail to state who owns the money. In Dreber, Ellingsen, Johanneson and Rand's and Kettner and Waichman's experiments the dictator possesses and touches the money in both treatments. In Grossman and Eckel's experiment, the dictators choose a payoff pair in the \$0\$20 range, thus making the same "allocation decision" in both treatments.

Other mediators may exist besides feelings of ownership. For example, the treatments in our experiment may affect how badly the dictator feels if the recipient's payoff is low. Dufwenberg, Gächter and Hennig-Schmidt (2011) examine the role of guilt aversion in public good games and Krupka, Leider and Jiang (forthcoming) examine its role in double dictator games. Dictators' anticipation of feelings of negative affect in the recipients may also influence behavior in our games. Thus, feelings of ownership may not be the only mediator in our experiment. 
A more speculative implication of our results refers to how philanthropies might use them to increase contributions. Our results establish that the payoff to the recipient is higher when the dictator has weak feelings of ownership. The implication is, therefore, that charitable contributions will be higher when the donor's feelings of ownership are weaker. Philanthropies could benefit by targeting individuals who view their income as "found" arising from good luck rather than earned. These individuals have low feelings of ownership. Philanthropies could also benefit by framing the donation as taking or opting out instead of giving or opting in. Finally, philanthropies could benefit by engaging donors so that they invest self with the philanthropy. 


\section{References}

Alchian, A.A., 2008. "Property Rights." The Concise Encyclopedia of Economics. Library of Economics and Liberty. Retrieved July 20, 2016 from the World Wide Web: http://www.econlib.org/library/Enc/PropertyRights.html

Banerjee, Priyodorshi and Sujoy Chakravarty, 2014. Psychological ownership, group affiliation and other-regarding behaviour: Some evidence from dictator games, Global Economics and Management Review, 19(1-2, January-December): 3-15

Brañas-Garza, Pablo, 2007. Promoting helping behavior with framing in dictator games. Journal of Economic Psychology, 28: 477-486.

Bushong, Benjamin, Lindsay M. King, Colin F. Camerer, and Antonio Rangel, 2010. Pavlovian Processes in Consumer Choice: The Physical Presence of a Good Increases Willingnessto-Pay. American Economic Review, 100 (September): 1-18.

Cherry, T.L., 2001. Mental accounting and other-regarding behavior: evidence from the lab. Journal of Economic Psychology, 22, 605-615.

Cherry, T.L., P. Frykblom and J.F. Shogren, 2002. Hardnose the dictator. American Economic Review, 92 (4): 1218-1221.

Cole, D. H. and P. Z. Grossman, 2002. The Meaning of Property Rights: Law versus Economics?' Land Economics, 78(3, August): 317-330.

Cox, J. C., J. A. List, M. Price, V. Sadiraj and A. Samek, 2015. Moral Costs and Rational Choice: Theory and Experimental Evidence. Working Paper: http://expecon.gsu.edu/center/working-papers.

Dreber, A., T. Ellingsen, M. Johannesson and D. G. Rand, 2013. Do people care about social context? Framing effects in dictator games. Experimental Economics, 16:349-371.

Engel, C., 2011. Dictator games: a meta study. Experimental Economics, 14, 583-610.

Greiner, B., 2015. Subject Pool Recruitment Procedures: Organizing Experiments with ORSEE, Journal of the Economic Science Association 1 (1), 114-125.

Grossman, P. J., and C. C. Eckel, 2015. Giving versus taking for a cause, Economics Letters 132 28-30 DOI: 10.1016/j.econlet.2015.04.002

Hayes, A. F. 2013. Introduction to mediation, moderation, and conditional process analysis. New York: The Guilford Press.

Hoffman, E., K. McCabe and V.L. Smith, 1994. Preferences, property rights, and anonymity in bargaining games. Games and Economic Behavior, 7, 346-380.

Hoffman, E. and M. Spitzer, 1985. Entitlements, rights, and fairness: an experimental examination of subjects' concepts of distributive justice. Journal of Legal Studies, 14, 259-297.

Kettner, Sara Elisa, and Israel Waichman, 2016. Old age and prosocial behavior: Social preferences or experimental confounds? Journal of Economic Psychology, 53: 118-130

Knetsch, Jack L. and Wei-Kang Wong, 2009. The endowment effect and the reference state: Evidence and manipulations. Journal of Economic Behavior \& Organization, 71(2, August): 407-413. 
Korenok, O., E. L. Millner and L. Razzolini, 2014. Taking, giving, and impure altruism in dictator games. Experimental Economics, 17(3):488-500

Oxoby, Robert J., John Spraggon, 2008. Mine and yours: Property rights in dictator games. Journal of Economic Behavior \& Organization, 65 (3-4, March), 703-713.

Peck, J. and S. B. Shu 2009. The Effect of Mere Touch on Perceived Ownership. Journal of Consumer Research, 36(3, October): 434-447. DOI: 10.1086/598614.

Pierce, J. L., Kostova, T. and K. T. Dirks, 2003. The state of psychological ownership: Integrating and extending a century of research. Review of General Psychology, 7(1), 84107. doi:10.1037/1089-2680.7.1.84

Reb, Jochen and Terry Connolly, 2007. Possession, feelings of ownership and the endowment effect. Judgment and Decision Making, 2(2, April): 107-114. 


\section{Appendix}

The appendix has seven parts.

1. Survey

2. Decision Sheet for the Recipient Earns-Take Treatment

3. Instructions to Recipients for the Recipient Earns-Take Treatment

4. Instructions to Dictators for the Recipient Earns-Take Treatment

5. Decision Sheet for the Dictator Earns-Give Treatment

6. Instructions to Recipients for the Dictator Earns-Give Treatment

7. Instructions to Dictators for the Dictator Earns-Give Treatment

\section{Survey}

What is the ID number on your index card? ID \#=

Please select a number that represents the extent to which you agree or disagree with the following statements about the money distributed in the game:

1. I feel like this is my money.

$\begin{array}{llllllllll}\text { Strongly Disagree } & 1 & 2 & 3 & 4 & 5 & 6 & 7 & \text { Strongly Agree }\end{array}$

2. I feel a very high degree of personal ownership of this money.

$\begin{array}{lllllllll}\text { Strongly Disagree } & 1 & 2 & 3 & 4 & 5 & 6 & 7 & \text { Strongly Agree }\end{array}$

3. I feel like I own this money.

$\begin{array}{llllllllll}\text { Strongly Disagree } & 1 & 2 & 3 & 4 & 5 & 6 & 7 & \text { Strongly Agree }\end{array}$

4. I feel like this is another person's money.

$\begin{array}{llllllllll}\text { Strongly Disagree } & 1 & 2 & 3 & 4 & 5 & 6 & 7 & \text { Strongly Agree }\end{array}$

5. I feel like another person has a very high degree of personal ownership of this money. $\begin{array}{lllllllll}\text { Strongly Disagree } & 1 & 2 & 3 & 4 & 5 & 6 & 7 & \text { Strongly Agree }\end{array}$

6. I feel like another person owns this money.

$\begin{array}{llllllllll}\text { Strongly Disagree } & 1 & 2 & 3 & 4 & 5 & 6 & 7 & \text { Strongly Agree }\end{array}$

7. I think that another person feels like this is her money.

$\begin{array}{lllllllll}\text { Strongly Disagree } & 1 & 2 & 3 & 4 & 5 & 6 & 7 & \text { Strongly Agree }\end{array}$

8. I think that another person feels a very high degree of personal ownership of this money. $\begin{array}{lllllllll}\text { Strongly Disagree } & 1 & 2 & 3 & 4 & 5 & 6 & 7 & \text { Strongly Agree }\end{array}$

9. I think that the other person feels like she owns this money.

$\begin{array}{lllllllll}\text { Strongly Disagree } & 1 & 2 & 3 & 4 & 5 & 6 & 7 & \text { Strongly Agree }\end{array}$




\section{Decision Sheet for the Recipient in the Earns-Take Treatment}

Step 1: The participant who earns the money completes items (1) and (2).

1. My ID number is (2) I earned \$

- Write your ID number on the envelope.

- Write your ID number in item (1). Your ID number is on the index card you received when you entered.

- Count the money in the envelope.

- Notify a monitor if the amount of money in the envelope differs from the amount in item (2).

- Put the money in your pocket, wallet, or purse.

- Put the Decision Sheet in the envelope and raise your hand.

Step 2: The participant who distributes the money completes item (3) and (4).

3. My ID number is

4. (4) I decided to take $\$$ from the other participant.

- Write your ID number in item (3). Your ID number is on the index card you received when you entered.

- Write the amount you decide to take in item (4) above and on line (2) of the Receipt.

- Write your ID number on the envelope.

- Put the Decision Sheet in the envelope and raise your hand.

Step 3: The participant who earned the money completes item (5).

5. I keep \$

- Write the amount you will keep in item (5). The amount you keep is item (2) item (4).

- Write the amount you will keep on line (2) of your Receipt.

- Put the amount of money written in item (4), if any, the two pieces of paper, and the Decision sheet in the envelope and raise your hand.

Step 4: The participant who distributes the money verifies that the amount of money in the envelope is correct.

- Verify that the amount of money in the envelope is equal to the amount in item (4)

- Notify a monitor if the amount of money in the envelope differs from the amount in item (4).

- Raise your hand when you are ready to proceed. 


\section{Instructions to Recipients in the Recipient Earns-Take Treatment}

You should have:

1. An index card with your ID number. We use the ID number to track participants in the experiment. We cannot use the ID number to learn your identity after the experiment is over.

2. Instructions

3. Sample Decision Sheet

4. Receipt

5. Exam

Please fill in the date, your social security or student ID number, your name, and your address on the top portion of the receipt while you wait for everyone to find a seat. Doing so will reduce the time spent processing payments at the end of the experiment. The University requires receipts for accounting purposes. The monitor in the room will not collect or see them. You will give them to an assistant sitting outside of the room when you leave.

You may read the following instructions silently after you complete the top portion of the receipt. The monitor will read them aloud after everyone is seated.

\section{Minimum age}

Please visit the monitor if you are 17 years old or younger. Research protocols at VCU require participants to be at least 18 years old.

\section{Anonymity}

Any interaction with other participants will be anonymous - you will never find out the identity of the participants you interacted with nor will they find out your identity. No one, including the researchers, will be able to identify your decisions. At the end of the experiment you will be paid privately and in cash. In order to keep your decisions private, do not talk with other participants during the experiment.

\section{Risks, benefits, and cost}

Participation in this experiment does not impose any risks in addition to those you encounter in your day-to-day activities. The primary benefit of the study will be to advance our understanding of decision-making in economic settings. You may gain some educational benefit. The only cost to you of participation is your time.

\section{Welcome}

This is an experiment in economic decision-making. You will receive a $\$ 5$ show-up fee. You will be asked to make a number of decisions. The decisions you and another participant make determine how much additional money you will receive at the conclusion of the experiment. A research foundation has provided the funds for this experiment. We estimate that you will complete the experiment within one hour and fifteen minutes.

Please raise your hand at any point if you have any questions about the instructions or if you wish to cease your participation. You may cease participation at any point; if you do you will receive the $\$ 5$ show-up fee but will not receive any additional compensation.

\section{The Experiment}


You will have 45 minutes to complete the exam you were given. The exam consists of 20 questions pulled from the GMAT and the GRE. You may work as much or as little as you would like on the exam.

The number of questions you answer correctly will determine how much money you earn. Specifically, if you correctly answer between 0 and 8 questions, you will earn $\$ 10$; if you correctly answer between 9 and 14 questions, you will earn $\$ 20$; if you correctly answer 15 or more questions, you will earn $\$ 40$.

After your exam has been graded, a monitor will deliver an envelope to you. The envelope will contain a Decision Sheet, the money you earned, and two dollar-sized pieces of paper. You will remove everything from the envelope, count the money to verify that the amount written in item (2) of the Decision Sheet is correct, and put the money and the two pieces of paper into your pocket, wallet, or purse. Follow the instructions for Step 1 on the Decision Sheet. Then put the Decision Sheet back into the envelope. The monitor will collect the envelope and give a survey to you to complete.

You will be paired randomly with another participant who will be sitting in another room in the building. The other participant will have an opportunity to review the same exam you completed to discern its difficulty. While she will not know your score on the exam, she will know how much money you earned, how it was determined by your score, and that you have put the money into a pocket, wallet, or purse.

The other participant will decide how much of the money you earned she will take from you for herself and how much you will keep. A monitor will transfer the envelope with the Decision Sheet to the other participant and she will record in item (4) on the Decision Sheet how much she decided to take.

After the other participant makes her decision, the Decision Sheet will be returned to you. You will remove the money the other Participant decided to take, if any, and the two pieces of paper from your pocket, wallet, or purse and put them into the envelope. You will then record how much of the money you have left in your pocket, wallet, or purse in item (5) of the Decision Sheet and line (2) of your receipt.

A monitor will take the envelope back to the other participant. She will verify that the amount of money in the envelope is equal to the amount of money she decided to take. After she verifies that the amount is correct, the experiment ends.

\section{Summary}

- You earn money based on your exam score.

- Another participant in another room decides how much of the money you earned to take from you and how much you keep.

\section{Instructions to Dictators in the Recipient Earns-Take Treatment}

You should have:

1. An index card with your ID number. We use the ID number to track participants in the experiment. We cannot use the ID number to learn your identity after the experiment is over.

2. Instructions

3. Sample Decision Sheet

4. Receipt 
Please fill in the date, your social security or student ID number, your name, and your address on the top portion of the receipt while you wait for everyone to find a seat. Doing so will reduce the time spent processing payments at the end of the experiment. The University requires receipts for accounting purposes. The monitor in the room will not collect or see them. You will give them to an assistant sitting outside of the room when you leave.

You may read the following instructions silently after you complete the top portion of the receipt. The monitor will read them aloud after everyone is seated.

\section{Minimum age}

Please visit the monitor if you are 17 years old or younger. Research protocols at VCU require participants to be at least 18 years old.

\section{Anonymity}

Any interaction with other participants will be anonymous-you will never find out the identity of the participants you interacted with nor will they find out your identity. No one, including the researchers, will be able to identify your decisions. At the end of the experiment you will be paid privately and in cash. In order to keep your decisions private, do not talk with other participants during the experiment.

\section{Risks, benefits, and cost}

Participation in this experiment does not impose any risks in addition to those you encounter in your day-to-day activities. The primary benefit of the study will be to advance our understanding of decision-making in economic settings. You may gain some educational benefit. The only cost to you of participation is your time.

\section{Welcome}

This is an experiment in economic decision-making. You will receive a $\$ 5$ show-up fee. You will be asked to make a number of decisions. The decisions you and another participant make determine how much additional money you will receive at the conclusion of the experiment. A research foundation has provided the funds for this experiment. We estimate that you will complete the experiment within one hour and fifteen minutes.

Please raise your hand at any point if you have any questions about the instructions or if you wish to cease your participation. You may cease participation at any point; if you do you will receive the $\$ 5$ show-up fee but will not receive any additional compensation.

\section{The Experiment}

You will be paired randomly with another participant who is sitting in another room in the building. The other participant had 45 minutes to complete an exam consisting of 20 questions pulled from the GMAT and the GRE. You have a copy of the exam on your table. The other participant could work as much or as little as she liked on the exam.

The number of questions the other participant answered correctly determined how much money she earned. Specifically, if she correctly answered between 0 and 8 questions, she earned $\$ 10$; if she correctly answered between 9 and 14 questions, she earned $\$ 20$; if she correctly answered 15 or more questions, she earned $\$ 40$. 
After the other participant has completed the exam, a monitor will give an envelope that contains a Decision Sheet to you. Remove the Decision Sheet and follow the instructions for Step 2.

The Decision Sheet will show the amount of money earned by the participant who took the exam. Although you do not have information on the participant's score on the exam, you can infer the range of her score from the above information. The other participant has counted the money to verify that the amount is correct and has put the money plus two dollar-sized pieces of paper in her pocket, wallet, or purse.

You must decide how much of the money the other participant earned you will take for yourself and how much the other participant will keep. Thus, if the other participant has earned \$20 (implying her score was between 10 and 14 correct answers) you must decide how much of this money you will take (an integer between $\$ 0$ and \$20) and how much the other participant will keep (an integer between $\$ 0$ and \$20). Please note that the amounts you take for yourself and the other participant keeps must sum to the amount of money the other participant earned.

Once you have decided how much to take, write the amount in item (4) on the Decision Sheet and on line (2) of your receipt. Then you will put the Decision Sheet back into the envelope. A monitor will collect the envelope and give you a survey to complete.

The monitor will take the Decision Sheet to the participant who took the exam. The other participant will remove the money you took, if any, plus the two pieces of paper from her pocket, wallet, or purse, and put them and the Decision Sheet in the envelope. A monitor will collect the envelope and deliver it back to you. You will remove the money and verify that the amount of money in the envelope is equal to the amount of money you decided to take. After you verify that the amount is correct, the experiment ends.

\section{Summary}

- A participant in another room earns money based on her exam score.

- You decide how much of the money the other participant earned to take for yourself and how the other participant keeps.

\section{Decision Sheet for the Dictator Earns-Give Treatment}

Step 1: The participant who earns the money completes items (1) - (4).

1. My ID number is

(2) I earned $\$$

$\circ \quad$ Write your ID number on the envelope. Your ID number is on the index card you received when you entered.

- Write your ID number in item (1).

- Count the money in the envelope.

- Notify a monitor if the amount of money in the envelope differs from the amount in item (2).

- Put the money in your pocket, wallet, or purse.

- Raise your hand.

- Complete items (3) and (4) after the monitor tells you to proceed.

3. I decided to give $\$$ to the other participant.

(4) I keep $\$$ 
- Write the amount you will give in item (3).

- Write the amount you will keep in item (4). The amount you keep is item (2) item (3).

- Write the amount you will keep on line (2) of your Receipt.

- Put the amount of money written in item (3), if any, the two pieces of paper, and the Decision sheet in the envelope and raise your hand.

Step 2: The participant who does not earn the money verifies that the amount of money in the envelope is correct.

- Verify that the amount of money in the envelope is equal to the amount in item (3)

- Notify a monitor if the amount of money in the envelope differs from the amount in item (3).

- Write the amount in item (3) on line (2) of your Receipt.

- Raise your hand when you are ready to proceed.

\section{Instructions to Recipients for the Dictator Earns-Give Treatment}

You should have:

1. An index card with your ID number. We use the ID number to track participants in the experiment. We cannot use the ID number to learn your identity after the experiment is over.

2. Instructions

3. Sample Decision Sheet

4. Receipt

Please fill in the date, your social security or student ID number, your name, and your address on the top portion of the receipt while you wait for everyone to find a seat. Doing so will reduce the time spent processing payments at the end of the experiment. The University requires receipts for accounting purposes. The monitor in the room will not collect or see them. You will give them to an assistant sitting outside of the room when you leave.

You may read the following instructions silently after you complete the top portion of the receipt. The monitor will read them aloud after everyone is seated.

\section{Minimum age}

Please visit the monitor if you are 17 years old or younger. Research protocols at VCU require participants to be at least 18 years old.

\section{Anonymity}

Any interaction with other participants will be anonymous-you will never find out the identity of the participants you interacted with nor will they find out your identity. No one, including the researchers, will be able to identify your decisions. At the end of the experiment you will be paid privately and in cash. In order to keep your decisions private, do not talk with other participants during the experiment.

\section{Risks, benefits, and cost}


Participation in this experiment does not impose any risks in addition to those you encounter in your day-to-day activities. The primary benefit of the study will be to advance our understanding of decision-making in economic settings. You may gain some educational benefit. The only cost to you of participation is your time.

\section{Welcome}

This is an experiment in economic decision-making. You will receive a $\$ 5$ show-up fee. The decisions another participant makes will determine how much additional money you will receive at the conclusion of the experiment. A research foundation has provided the funds for this experiment. We estimate that you will complete the experiment within one hour and fifteen minutes.

Please raise your hand at any point if you have any questions about the instructions or if you wish to cease your participation. You may cease participation at any point; if you do you will receive the $\$ 5$ show-up fee but will not receive any additional compensation.

\section{The Experiment}

In each of your folders is an exam consisting of 20 questions pulled from the GMAT and the GRE. In a separate room, another participant has had 45 minutes to complete the same exam.

The number of questions the other participant answers correctly determined how much money the other participant earned. Specifically, if she correctly answered between 0 and 8 questions, she earned $\$ 10$; if she correctly answered between 9 and 14 questions, she earned \$20; if she correctly answered 15 or more questions, she earned $\$ 40$.

The other participant must decide how much of the money she earned to give to you and how much to keep for herself. Specifically, a monitor will give her an envelope that contains the money she earned and a Decision Sheet. She will count the money to verify that the amount written on the Decision Sheet is correct and put the money in her wallet, purse, or pocket. Then she will use the Decision Sheet to indicate how much she gives to you. She removes the money she gives to you, if any, from her wallet, purse, or pocket and puts it back into the envelope. She keeps the remainder. She also puts two dollar-sized pieces of paper in the envelope.

After the other participant makes her decision, a monitor will bring the envelope to you. You will remove the contents and count the money to verity that the amount of money in the envelope equals the amount written on item (3) of the Decision Sheet. After you verify that the amount is correct, the experiment ends.

\section{Summary}

- Another participant in another room earns money based on her exam score.

- The other participant decides how much of the money to give to you and how much to keep for herself.

\section{Instructions to Dictators for the Dictator Earns-Give Treatment}

You should have:

1. An index card with your ID number. We use the ID number to track participants in the experiment. We cannot use the ID number to learn your identity after the experiment is over.

2. Instructions 
3. Sample Decision Sheet

4. Receipt

5. Exam

Please fill in the date, your social security or student ID number, your name, and your address on the top portion of the receipt while you wait for everyone to find a seat. Doing so will reduce the time spent processing payments at the end of the experiment. The University requires receipts for accounting purposes. The monitor in the room will not collect or see them. You will give them to an assistant sitting outside of the room when you leave.

You may read the following instructions silently after you complete the top portion of the receipt. The monitor will read them aloud after everyone is seated.

\section{Minimum age}

Please visit the monitor if you are 17 years old or younger. Research protocols at VCU require participants to be at least 18 years old.

\section{Anonymity}

Any interaction with other participants will be anonymous-you will never find out the identity of the participants you interacted with nor will they find out your identity. No one, including the researchers, will be able to identify your decisions. At the end of the experiment you will be paid privately and in cash. In order to keep your decisions private, do not talk with other participants during the experiment.

\section{Risks, benefits, and cost}

Participation in this experiment does not impose any risks in addition to those you encounter in your day-to-day activities. The primary benefit of the study will be to advance our understanding of decision-making in economic settings. You may gain some educational benefit. The only cost to you of participation is your time.

\section{Welcome}

This is an experiment in economic decision-making. You will receive a $\$ 5$ show-up fee. You will be asked to make a number of decisions. The decisions you make will determine how much additional money you will receive at the conclusion of the experiment. A research foundation has provided the funds for this experiment. We estimate that you will complete the experiment within one hour and fifteen minutes.

Please raise your hand at any point if you have any questions about the instructions or if you wish to cease your participation. You may cease participation at any point; if you do you will receive the $\$ 5$ show-up fee but will not receive any additional compensation.

\section{The Experiment}

You will have 45 minutes to complete the exam you were given. The exam consists of 20 questions pulled from the GMAT and the GRE. You may work as much or as little as you would like on the exam.

The number of questions you answer correctly will determine how much money you earn. Specifically, if you correctly answer between 0 and 8 questions, you will earn $\$ 10$; if you correctly answer between 9 and 14 questions, you will earn $\$ 20$; if you correctly answer 15 or more questions, you will earn $\$ 40$. 
After your exam has been graded, a monitor will deliver an envelope to you. The envelope will contain a Decision Sheet, the money you earned, and two dollar-sized pieces of paper. Please remove everything from the envelope, count the money to verify that the amount written in item (2) of the Decision Sheet is correct, and put the money and the two pieces of paper into your pocket, wallet, or purse.

You will be paired randomly with another participant who will be sitting in another room in the building. The other participant will have an opportunity to review the same exam you completed to discern its difficulty. While she will not know your score on the exam, she will know how much money you earned and how it was determined by your score.

After the monitor tells you to proceed, you will decide how much of the money you earned to give to the other participant and how much to keep for yourself. Thus, if you have generated \$20 (implying your score was between 10 and 14 correct answers) you must decide how much of this money you will give (an integer between $\$ 0$ and $\$ 20$ ) and how much you will keep to keep (an integer between $\$ 0$ and $\$ 20$ ). Please note that the amounts you give and you keep must sum to the amount of money you earned.

After decide how much of the money you earned to give to the other participant, you will write your decision on item (3) of the Decision Sheet. You will take the amount of money you chose, if any, out of your pocket, wallet, or purse and put it and the two pieces of paper in the envelope. You will write the money you keep on item (4) of the Decision Sheet and on line (2) of the Receipt.

After you make your decision, please put the Decision Sheet in the envelope and raise your hand. A monitor will collect the envelope, give you a survey to complete, and take the envelope to the other participant. The other participant will count the money in the envelope to verify that the amount in the envelope is the amount you decided to give. After she verifies that the amount is correct, the experiment ends.

\section{Summary}

- You generate money based on your exam score

You decide how much of the money you earned to give to another participant and how much to keep for yourself. 